\title{
Molecular characteristic of activin receptor IIB and its functions in growth and nutrient regulation in Eriocheir sinensis
}

Jingan Wang ${ }^{1}$, Kaijun Zhang ${ }^{1}$, Xin Hou ${ }^{1}$, Wucheng Yue ${ }^{1}$, He Yang ${ }^{1}$, Xiaowen Chen ${ }^{1}$, Jun Wang ${ }^{1}$, Chenghui Wang

${ }^{1}$ Key Laboratory of Freshwater Fisheries Germplasm Resources, Ministry of Agriculture and Rural Affair / National Demonstration Center for Experimental Fisheries Science Education / Shanghai Engineering Research Center of Aquaculture, Shanghai Ocean University, Shanghai, China

Corresponding Author: Chenghui Wang

Email address: wangch@shou.edu.cn

Activin receptor IIB (ActRIIB) is a serine/threonine-kinase receptor binding with transforming growth factor- $\beta$ (TGF- $\beta$ ) superfamily ligands to participate in the regulation of muscle mass in vertebrates. However, its structure and function in crustaceans remain unknown. In this study, the ActRIIB gene in Eriocheir sinensis (Es-ActRIIB) was cloned and obtained with a $1683 \mathrm{bp}$ open reading frame, which contains the characteristic domains of TGF- $\beta$ type II receptor superfamily, encoding 560 amino acids. The mRNA expression of EsActRIIB was the highest in hepatopancreas and the lowest in muscle at each molting stage. After injection of Es-ActRIIB double-stranded RNA during one molting cycle, the RNA interference (RNAi) group showed higher weight gain rate, higher specific growth rate, and lower hepatopancreas index compared with the control group. Meanwhile, the RNAi group displayed a significantly increased content of hydrolytic amino acid in both hepatopancreas and muscle. The RNAi group also displayed slightly higher contents of saturated fatty acid and monounsaturated fatty acid but significantly decreased levels of polyunsaturated fatty acid compared with the control group. After RNAi on Es-ActRIIB, the mRNA expressions of five ActRIIB signaling pathway genes showed that $A c t R I$ and forkhead box $\mathrm{O}(\mathrm{FoxO})$ were downregulated in hepatopancreas and muscle, but no significance expression differences were found in small mother against decapentaplegic (SMAD) 3 , SMAD4 and mammalian target of rapamycin. The mRNA expression $\mathrm{s}$ of three lipid metabolism-related genes (carnitine palmitoyltransferase $1 \beta(C P T 1 \beta)$, fatty acid synthase, and fatty acid elongation) were significantly downregulated in both hepatopancreas and muscle with the exception of $C P T 1 \beta$ in muscles. These results indicate that $A c t R I I B$ is a functionally conservative negative regulator in growth mass, and protein and lipid metabolism could be affected by inhibiting ActRIIB signaling in crustacean. 
1

\section{Molecular characteristic of activin receptor IIB and its}

3 functions in growth and nutrient regulation in

4 Eriocheir sinensis

7 Jingan Wang, Kaijun Zhang, Xin Hou, Wucheng Yue, He Yang, Xiaowen Chen, Jun Wang,

8 Chenghui Wang

Key Laboratory of Freshwater Fisheries Germplasm Resources, Ministry of Agriculture and

11 Rural Affair / National Demonstration Center for Experimental Fisheries Science Education /

12 Shanghai Engineering Research Center of Aquaculture, Shanghai Ocean University, Shanghai,

13 China

14

15 Corresponding Author:

16 Chenghui Wang

17

18

Email address: wangch@shou.edu.cn

19 


\section{Abstract}

21 Activin receptor IIB (ActRIIB) is a serine/threonine-kinase receptor binding with transforming growth factor- $\beta$ (TGF- $\beta$ ) superfamily ligands to participate in the regulation of muscle mass in vertebrates. However, its structure and function in crustaceans remain unknown. In this study, the ActRIIB gene in Eriocheir sinensis (Es-ActRIIB) was cloned and obtained with a $1683 \mathrm{bp}$ open reading frame, which contains the characteristic domains of TGF- $\beta$ type II receptor superfamily, encoding 560 amino acids. The mRNA expression of $E s-A c t R I I B$ was the highest in hepatopancreas and the lowest in muscle at each molting stage. After injection of Es-ActRIIB double-stranded RNA during one molting cycle, the RNA interference (RNAi) group showed higher weight gain rate, higher specific growth rate, and lower hepatopancreas index compared with the control group. Meanwhile, the RNAi group displayed a significantly increased content of hydrolytic amino acid in both hepatopancreas and muscle. The RNAi group also displayed slightly higher contents of saturated fatty acid and monounsaturated fatty acid but significantly decreased levels of polyunsaturated fatty acid compared with the control group. After RNAi on $E s$-ActRIIB, the mRNA expressions of five ActRIIB signaling pathway genes showed that ActRI and forkhead box $\mathrm{O}(\mathrm{Fox} O)$ were downregulated in hepatopancreas and muscle, but no significance expression differences were found in small mother against decapentaplegic (SMAD) 3, SMAD4 and mammalian target of rapamycin. The mRNA expressions of three lipid metabolism-related genes (carnitine palmitoyltransferase $1 \beta(C P T 1 \beta)$, fatty acid synthase, and fatty acid elongation) were significantly downregulated in both hepatopancreas and muscle with the exception of $C P T 1 \beta$ in muscles. These results indicate that ActRIIB is a functionally conservative negative regulator in growth mass, and protein and lipid metabolism could be affected by inhibiting ActRIIB signaling in crustacean.

Keywords: Eriocheir sinensis, ActRIIB, gene expression, RNA interference, functional characterization 


\section{Introduction}

48 In vertebrates, the transforming growth factor- $\beta$ (TGF- $\beta$ ) superfamily consists of a large number

49 of structurally and functionally related cytokine subfamilies, including TGF- $\beta$ s, bone

50 morphogenetic proteins (BMPs), activins, and growth differentiation factors (GDFs), which

51 regulate a series of biological processes, such as cell differentiation, muscle growth, and

52 embryonic development (Santibanez, Quintanilla \& Bernabeu, 2011; Morikawa, Derynck \&

53 Miyazono, 2016). The TGF- $\beta$ family members exert their biological functions via two

54 heteromeric complexes of transmembrane proteins, namely, type I and type II receptors

55 (TGFBR1 and TGFBR2, respectively), and activate the small mother against decapentaplegic

56 (SMAD)-dependent or SMAD-independent signaling pathways (Hata \& Chen, 2016; Nickel, Ten

$57 \&$ Mueller, 2018). The activin receptor type IIB (ActRIIB), a serine/threonine kinase

58

59

60

61

62

63

64

65

66

67

68

69

70

71

72

73

74

75

76

77

78

79

80

81

82

83

84

85 transmembrane receptor, can bind diverse members (ligands) of the TGF- $\beta$ family, including activins A, BMP-2, BMP-7, GDF-8 (myostatin) and GDF-11 (Sako et al., 2010). ActRIIB regulates muscle growth, embryonic development, and reproduction in vertebrates (Chen et al., 2015; Morvan et al., 2017). In invertebrates, the conserved structure of ActRIIB was first identified in Xenopus in 1992; it plays an important role in the development of the TGF- $\beta$ family (Mathews,Vale \& Kintner, 1992; Dyson \& Gurdon, 1997).

ActRIIB signaling, besides its effect on muscle growth, can also regulate (improve or inhibit) adipogenesis (Bielohuby, 2012; Li et al., 2016). Fat contents were reduced drastically in highfat-diet mice by blockade of ActRIIB signaling (Akpan et al., 2009; Koncarevic et al., 2012), and the interference on $A c t R I I B$ improved lipid profiles and prevented hepatic fat accumulation compared with the mice fed with the same high-fat diet but treated with vehicle only (Bielohuby, 2012). Therefore, the inhibition of ActRIIB signaling has become a novel therapeutic approach in improving obesity and obesity-linked metabolic diseases (Koncarevic et al., 2012). This strategy induces changes in the expression patterns of fat metabolism-related genes in adipose tissues (Koncarevic et al., 2012; Xin et al., 2019). However, the molecular mechanism underlying ActRIIB-mediated metabolic process remains poorly understood in animals.

In crustaceans, the TGF- $\beta$ superfamily members display multifunctional characteristics in regulating growth, metabolism, immune response, and appendage regeneration (Klinbunga et al., 2018; Zhou et al., 2018; Shinji et al., 2019; Zhou et al., 2019). In particular, myostatin, which is a negative growth regulator in vertebrates, is involved in complex and potentially multimodal actions in crustaceans (Lee et al., 2015; Mykles \& Medler, 2015; Abuhagr et al., 2016; Zhuo et al., 2017; Yue et al., 2020). This condition demonstrates that the TGF- $\beta$ superfamily members perform different biological actions in crustaceans and vertebrates. As an important receptor of myostatin, ActRIIB gene has become a powerfully therapeutic target to improve individual weight in vertebrates. However, its structure and functions in crustaceans remain unknown. 
86

87

88

89

90

91

92

93

94

95

96

97

98

99

100

101

102

103

104

105

106

107

108

109

110

111

112

113

114

115

116

117

118

119

120

121

122

123

124

125

The Chinese mitten crab (Eriocheir sinensis) is an important economic crab species with huge aquaculture industry in China; however, it is considered an invasive species in Europe and North America (Huang et al., 2015; Wang et al., 2018). Recently, the mRNA structure and expression of TGFBR1 were reported in E. sinensis, and the functions of TGF- $\beta$-like signaling mediated by $T G F B R 1$ in molting-related muscle growth were elucidated in crustaceans (Tian et al., 2019b). As an important receptor of TGF- $\beta$ superfamily members, the structure, expression, and biological actions of ActRIIB in regulating growth and muscle mass have not been identified in E. sinensis. Furthermore, in our recent studies, myostatin exhibited complex and multimodal actions in E. sinensis (Yue et al., 2020). As a member of the myostatin/ActRIIB signal pathway, the complex and multi-model actions of ActRIIB in E. sinensis must be characterized. In the present study, we first identified the structural characteristics and expression profiles of ActRIIB in $E$. sinensis ( $E s-A c t R I I B)$ in various tissues during different molting stages. Then, we conducted RNA interference (RNAi) on Es-ActRIIB to investigate molting/growth characteristics, tissue compositions, and expression levels of metabolism-related genes in $E$. sinensis. This study aimed to characterize the Es-ActRIIB gene and determine the multifunctions of ActRIIB in crustacean.

\section{Materials and Methods}

\section{Animal and tissue collection}

Healthy samples of juvenile E. sinensis with a mean weight of $8.38 \pm 0.52 \mathrm{~g}$, whole appendages, and good vitality were collected from the Aquatic Animal Germplasm Station of Shanghai Ocean University. The crabs were raised in a recirculation aquaculture system with the temperature maintained at $27^{\circ} \mathrm{C} \pm 0.5^{\circ} \mathrm{C}$ and fed twice daily with commercial diets (Yue et al., 2020). To detect the expression profiles of Es-ActRIIB, we collected 11 different tissues of each crab, including the eyestalk, hepatopancreas, heart, gills (mixed front and back gills), stomach, intestine, walking leg muscle, claw muscle, pectoral muscle, thoracic ganglia, and epidermis, in the postmolt, intermolt, premolt and ecdysis stages, which were determined in accordance with the seta morphological characteristics of mandible described by Chan et al (1988). All the collected tissue samples were flash-frozen in liquid nitrogen and subsequently stored at $-80{ }^{\circ} \mathrm{C}$ for further analysis. Sampling procedures complied with the guidelines of the Animal Care and Use Committee of Shanghai Ocean University (SHOU-DW-2017021) on the care and use of animals for scientific purposes.

\section{RNA extraction and cDNA synthesis}

The total RNA was extracted using the RNA iso-Plus (Takara, Japan) following the manufacturer's instructions. The concentration of extracted RNAs was examined by a spectrophotometer (Eppendorf BioSpectrometer ${ }^{\circledR}$ basic, Hamburg, Germany), and the RNA integrity was detected by $1 \%$ agarose gel electrophoresis. The RNAs with an OD 260/280 value ranging from 1.8 to 2.0 were used for cDNA synthesis. The templates used for full-length cDNA sequence cloning were synthesized by the SMARTer RACE 5'/3' cDNA Kit Components 
126 (Clontech, USA). The templates used for quantitative real-time polymerase chain reaction (qRT127 PCR) were synthesized by using the PrimeScript ${ }^{\mathrm{TM}} \mathrm{RT}$ reagent Kit with gDNA Eraser (TaKaRa,

128 Japan) in accordance with the manufacturer's instructions.

129

\section{Cloning of Es-ActRIIB}

131

132

133

134

135

136

137

138

139

140

141

142

143

144

145

146

147

148

149

150

151

152

153

154

155

156

157

158

159

160

161

162

163

164

The primers for cloning of Es-ActRIIB were designed using Primer Premier 5.0 software based on transcriptome annotation results of $E$. sinensis in our previous study (Huang et al., 2015)

(Table S1). The total volume of the PCR reaction was $20 \mu \mathrm{L}$, including $10 \mu \mathrm{L} 2 \times$ Hieff $^{\circledR}$ Master Mix, $1 \mu \mathrm{L}$ cDNA template, $0.5 \mu \mathrm{L} 10 \mathrm{pmol} / \mu \mathrm{L}$ forward primer and $0.5 \mu \mathrm{L} 10 \mathrm{pmol} / \mu \mathrm{L}$ reverse primer, and $8 \mu \mathrm{L}$ double-distilled water $\left(\mathrm{ddH}_{2} \mathrm{O}\right)$. The PCR programs were run as follows: $94{ }^{\circ} \mathrm{C}$ for $5 \mathrm{~min}$; 30 cycles of $94{ }^{\circ} \mathrm{C}$ for $30 \mathrm{~s}, 60^{\circ} \mathrm{C}$ for $30 \mathrm{~s} ; 72{ }^{\circ} \mathrm{C}$ for $1 \mathrm{~min}$; then $72{ }^{\circ} \mathrm{C}$ for $7 \mathrm{~min}$. The PCR products were examined using $1 \%$ agarose gel. Then, the purified PCR products were ligated with pMD19-T Vector (TaKaRa, Japan) and transformed into Escherichia coli DH5 $\alpha$ competent cell (TaKaRa, Japan). The positive colonies were sent to Sangon Biotech Company (Shanghai, China) for sequencing.

\section{Bioinformatics analysis of Es-ActRIIB}

The protein sequence of Es-ActRIIB was deduced by ExPASY-translate tool (http://www.expasy.org/). The sequence alignment analysis was performed using the National Center for Biotechnology Information-Basic Local Alignment Search Tool (http://www.ncbi.nlm.nih.gov/blast). The protein domains were predicted by Simple Modular Architecture Research Tool (http://smart.embl-heidelberg.de/) and modeled by Iterative Threading ASSEmbly Refinement server (https://zhanglab.ccmb.med.umich.edu/I-TASSER/). A phylogenetic tree was constructed by MEGA 7.0 software using neighbor-joining methods with a bootstrap value of 1000 (Table S2).

\section{Tissue expression detection of Es-ActRIIB}

The mRNA expression of Es-ActRIIB in 11 tissues in the four molting stages were detected using $10 \mu \mathrm{L}$ Hieff UNICON ${ }^{\circledR}$ qPCR SYBR Green Master Mix, including $1 \mu \mathrm{L}$ cDNA, $1 \mu \mathrm{L}$ primer Mix, and $8 \mu \mathrm{LddH}_{2} \mathrm{O}$. Four biological replicates and three experimental replicates were employed in the detected each tissue from each molting stage. The reaction program was run as follows: $95^{\circ} \mathrm{C}$ for $30 \mathrm{~s}$, followed by 40 cycles of $95^{\circ} \mathrm{C}$ for $5 \mathrm{~s}$ and $60^{\circ} \mathrm{C}$ for $30 \mathrm{~s}$. The temperature was increased by $0.5^{\circ} \mathrm{C}$ per $5 \mathrm{~s}$ from $60^{\circ} \mathrm{C}$ to $95^{\circ} \mathrm{C}$ for the melting curve with $30 \mathrm{~s}$ elapse time per cycle. $\beta$-Actin, $S 27$, and $U B E$ were selected as reference genes (Huang et al., 2017), and the relative expression levels of target genes were accurate normalizatied by geometric averaging of this three reference genes with the method of $\Delta \Delta \mathrm{Ct}$ (Vandesompele et al., 2002; Hellemans et al., 2007). The primers for qRT-PCR were listed in Table S1.

\section{RNAi}


165 The target segment containing numerous functional short-interfering RNA sites was predicted

166

167

168

169

170

171

172

173

174

175

176

177

178

179

180

181

182

183

184

185

186

187

188

189

190

191

192

193

194

195

196

197

198

199

200

201

202

203

204

using siDirect version 2.0 (http://sidirect2.rnai.jp/) to obtain an effective double-stranded RNA (dsRNA) of Es-ActRIIB. The designed primers included a T7 RNA polymerase-binding site at the $5^{\prime}$-end (Table S1). The dsRNA was synthesized using T7 RiboMAX ${ }^{\mathrm{TM}}$ Large Scale RNA Production Systems (Promega, P1300) in accordance with the manufacturer's instructions. To test the efficiency of the designed dsRNA, we injected six individuals with $3 \mu \mathrm{g} / \mathrm{g}$ dsRNA (1 $\mu \mathrm{g} / \mathrm{mL}$ ) as the experimental group and injected another six individuals with phosphatebuffered saline (PBS) $(3 \mu \mathrm{L} / \mathrm{g})$ as the control group. qRT-PCR was conducted to test the expression of $E s-A c t R I I B$ for investigating the interference efficiency. Sixty individual crabs $(4.62 \pm 0.78 \mathrm{~g})$ were collected immediately after molting and divided randomly and equally into two groups, namely, the RNAi (injected with dsRNA) and control (injected with PBS) groups, to explore the function of Es-ActRIIB in growth during the molting process. All crabs were individually raised in the same recirculation aquaculture system with the temperature maintained at $27^{\circ} \mathrm{C} \pm 0.5^{\circ} \mathrm{C}$ and fed twice daily with commercial diets. The first injection was conducted on the 5th day after crab molting and continued every 5 days until the end of the second molting. At the end of the experiment, each survivor was weighed, sacrificed, and then dissected for analysis of gene expression and tissue composition.

\section{Basic growth characteristic measurement}

According to our previous study (Yue et al., 2020), the body weight $(B W)$ and hepatopancreas weight $(H W)$ of each crab were measured on the third day after molting, and molting interval time ( $M I$, the days between the first and second molting) was recorded for each individual. The weight gain rate $(W G R)$, specific growth rate $(S G R)$, and hepatopancreas index $(H I)$ were respectively calculated as follows:

$$
\begin{aligned}
& W G R=\left(B W_{2}-B W_{1}\right) / B W_{1} \times 100 \% \\
& S G R=\left(\operatorname{Ln} B W_{2}-\operatorname{Ln} B W_{1}\right) / M I \\
& H I=\left(H W / B W_{2}\right) \times 100 \%
\end{aligned}
$$

where $B W_{1}$ and $B W_{2}$ are the $B W$ after the first and second molting, respectively.

\section{Tissue composition analysis}

At the end of the RNAi experiment, the hepatopancreatic and whole muscle tissues of each crab were sampled for fatty acid and hydrolytic amino acid composition analysis by using gas chromatography and mass spectrometry and amino acid automatic analysis apparatus, respectively (Wei et al., 2018).

\section{Expression detection of target genes}

Similarly, at the end of the RNAi experiment, six crabs from the RNAi and control groups were sampled, and their hepatopancreas and leg muscle tissues were collected for qRT-PCR detection of the target genes, including five ActRIIB signaling pathway genes (ActRI, SMAD3, SMAD4, forkhead box $\mathrm{O}($ FoxO $)$, and mammalian target of rapamycin (mTOR)) (Han et al., 2013; Guru et 
205

206

207

208

209

210

211

212

213

214

215

216

217

218

219

220

221

222

223

224

225

226

227

228

229

230

231

232

233

234

235

236

237

238

239

240

241

242

243

244

al., 2019), and three lipid metabolism-related genes (carnitine palmitoyltransferases $1 \beta(C P T 1 \beta)$, fatty acid synthase $(F A S)$, and fatty acid elongation $(F A E)$ ) (Liu et al., 2016; DeBose-Boyd, 2018; Liu et al., 2018). The qRT-PCR procedures were similar to those for Es-ActRIIB expression detection. Table $\mathbf{S 1}$ lists all the primers for the qRT-PCR reactions.

\section{Statistical analysis}

All data about gene expression, growth characteristic, and tissue composition were statistically analyzed by one-way analysis of variance followed by Duncan's multiple range test with SPSS 20. $P<0.05$ was considered statistically significant.

\section{Results}

\section{cDNA sequence of Es-ActRIIB}

The full-length cDNA sequence of Es-ActRIIB was 4916 bp (GenBank accession number: MN832896), including a 618 bp 5' terminal untranslated region (5'-UTR), a 1683 bp of open reading frame (ORF), and a 2615 bp 3'-UTR. The ORF encodes 560 amino acids (aa) with a predicted molecular weight of $62.86 \mathrm{kDa}$ and a theoretical isoelectric point of 6.00 (Fig. S1). The predicted domains of Es-ActRIIB contain an activin receptor domain (46-140 aa) and a serine/threonine protein kinase domain (251-539 aa), which are characteristic domains of TGFBR2 superfamily. A signal peptide and a transmembrane region were located at the 1-28 aa and 198-220 aa, respectively (Fig. 1A). The tertiary structure of Es-ActRIIB consists of $13 \alpha-$ helices and $7 \beta$-sheets (Fig. 1B and 1C).

\section{Sequence alignment and phylogenetic analysis}

BLAST analysis showed that Es-ActRIIB protein sequence shared high identities with Portunus trituberculatus (92\%; GenBank: MPC26231.1), Penaeus vannamei (69\%; GenBank:

ROT74806.1), Daphnia magna (54\%; GenBank: JAL80963.1) and Nasonia vitripennis (GenBank: XP_001603863.1) and other insects (50\%-60\%). The phylogenetic tree of ActRIIB could be divided into two large branches. ActRIIBs from arthropods were clustered together in one large branch, in which Es-ActRIIB was clustered closely with ActRIIBs of crustaceans. ActRIIBs of fishes, amphibians, mammals, reptiles and bird species were clustered together in another branch (Fig. 2).

\section{Tissue expression profiles of Es-ActRIIB}

The mRNA expression of Es-ActRIIB could be detected in all 11 tissues during the four molting stages (Fig. 3). Although significant differences were observed among tissues at the same molting stage, the mRNA expression of Es-ActRIIB in hepatopancreas was the highest $(P<0.05)$ and the lowest in muscles (walking leg muscle, claw muscle, pectoral muscle) at each molting stage. Comparison of the four molting stages revealed the highest expression $(P<0.05)$ of $E s$ $A c t R I I B$ gene was detected in hepatopancreas and three muscle tissues at the premolt stage. 


\section{Growth characteristics after RNAi on Es-ActRIIB}

246 After injection of synthesized dsRNA, the mRNA expression of Es-ActRIIB significantly

247 decreased by $60.84 \%(P<0.01)$ in the RNAi group compared with the control group at $48 \mathrm{~h}$

248 (Fig. 4), demonstrating the high efficiency of the designed dsRNA on Es-ActRIIB. After 249 continuous injection during one molting cycle, the $W G R$ increased by $53.55 \%$, and the $S G R$

250 increased by $64.71 \%$ in the RNAi group $(P<0.01)$ compared with the control group. In addition, 251 the $H I$ in the RNAi group (5.26 \pm 0.58$)$ was significantly lower than that of the control group $252(7.09 \pm 0.55)(P<0.01)$. No significant difference was found in the $M I$ between the RNAi and 253 control groups $(P>0.05)$ (Table 1).

254

255

256

257

258

259

260

261

262

263

264

265

266

267

268

269

270

271

272

273

274

275

276

\section{Discussion}

278 In the present study, characterization of Es-ActRIIB indicated that the encoded protein sequence 279 of this gene has the characteristic structural domains of TGFBR2 members (Thompson, Woodruff \& Jardetzky, 2003). In vertebrates, ActRIIB binds to activin and myostatin ligands through its extracellular activin receptor domain, and its intracellular serine/threonine protein 
284 sinensis, similar to that in vertebrates, implying that Es-ActRIIB might play the same role in 285 TGF- $\beta$ signal transduction as in vertebrates.

286

287

288

289

290

291

292

293

294

295

296

297

298

299

300

301

302

303

304

305

306

307

308

309

310

311

312

313

314

315

316

317

318

319

320

321

322

323

ActRIIB is widely distributed in various tissues and developmental stages in mouse, zebrafish, and other vertebrates (Garg et al., 1999; Rebbapragada et al., 2003), consistent with our findings showing that $E s-A c t R I I B$ was widely expressed in all tested tissues at different molting stages; the findings also indicate the similar expression profiles in crustaceans and vertebrates. Molting is the special growth biological process of E. sinensis, and the transcription levels of numerous related genes in vivo change with molting cycle (Huang et al., 2015). The expression profiles of Es-ActRIIB in different tissues showed significant changes in the four molting stages, revealing that $A c t R I I B$ is involved in molting-related growth regulation in E. sinensis. Interestingly, Es$A c t R I I B$ showed the highest expression in the hepatopancreas in the four molting stages; this finding might be relevant to growth metabolism because hepatopancreas is an important organ underlying carbohydrate and lipid metabolism, nutritional status, energy storage, and breakdown in crustaceans (Wang et al., 2008). Meanwhile, the mRNA expression of Es-ActRIIB in all three types of muscles peaked at the premolt stage during the molting process, implying that this gene is involved in muscle atrophy induced by molting.

To explore the function of $E s-A c t R I I B$ in growth regulation, we successfully knocked down the transcription level of ActRIIB in E. sinensis. The Es-ActRIIB mRNA knocked-down crabs in this study showed fast weight gain rate and specific growth rate. This finding confirms the result of RNAi on ActRIIB in dystrophic mdx mice (Dumonceaux et al., 2010). Moreover, the high contents of TEAA, TNEAA and TAA in muscle and hepatopancreas indicated that the fast growth of Es-ActRIIB knocked-down individuals was caused by the acceleration of protein synthesis. The myostatin/ActRIIB signal pathway regulating muscle protein balance has been identified in vertebrates (Han et al., 2013). ActRI is the interacting protein of ActRIIB binding to myostatin (Hata \& Chen, 2016), and its lower expression was observed with interference of $E s$ ActRIIB in this study; the expressions of downstream transcription factors SMAD3 and SMAD4 were not influenced, the reason probably was that $S M A D$ s, as core and versatile cytokines, are active in the TGF- $\beta$ pathway, including the signal transduction of TGF- $\beta /$ BMP/activin, not only in myostatin/ActRIIB pathway (Massague, Seoane \& Wotton, 2005; Tian et al., 2018b). Moreover, in the process of muscle protein balance, ActRIIB signal pathway stimulates FoxOdependent transcription to enhance muscle protein catabolism and suppresses $A k t / m T O R$ signaling to inhibit muscle protein synthesis (Han et al., 2013; Hulmi et al., 2013; Tian et al., 2018a; Tian et al., 2019a). Although the expression of $m$ TOR was not influenced after dsRNA injection of $E s-A c t R I I B$, the low expression of $F o x O$ was observed, resulting in the slowed down protein catabolism that is needed to accelerate muscle protein synthesis. This result was also consistent with the high TEAA, TNEAA and TAA contents, rapid weight gain rate, and specific growth rate. Therefore, the results imply that the interference of $E s-A c t R I I B$ accelerated individual growth by regulating protein catabolism and synthesis pathways.

Peerj reviewing PDF | (2020:01:44950:3:0:NEW 7 Jul 2020) 
324

325

326

327

328

329

330

331

332

333

334

335

336

337

338

339

340

341

342

343

344

345

346

347

348

349

350

351

352

353

354

355

356

357

358

359

360

361

362

Hepatopancreas is the main organ for lipid storage and lipid processing in crustaceans (Wang et al., 2008). A low $H I$ was noted after RNAi on $E s$-ActRIIB, and the same result was observed in E. sinensis after interference of ES-MSTN (Yue et al., 2020); a similar phenotype was reported in vertebrates, showing that the inhibition of $A c t R I I B$ signaling decreases adipogenesis in adipose tissues (Koncarevic et al., 2012; Morrison et al., 2014). These studies indicated that lipid synthesis could be blocked by inhibiting ActRIIB signaling. Accordingly, the fatty acid composition changed significantly in the hepatopancreas, demonstrating that lipid metabolism was affected. Furthermore, $F A E$ is responsible for long chain fatty acid elongation (Igarashi et al., 2019); the findings showed that low expression of $F A E$ in hepatopancreas after Es-ActRIIB interference denotes a slowed down lipid synthesis, which was supported by the low HI. CPT1 $\beta$ is the key enzyme of $\beta$-oxidation of fatty acids; the downregulated expression of $C P T 1 \beta$ in hepatopancreas might imply that energy consumption is reduced in hepatopancreas to support muscle growth, and upregulated expression in muscle indicates that lipolysis is activated and enhanced in muscle to generate additional energy for growth (Huang et al., 2015; Liu et al., 2018; Yue et al., 2020). Moreover, FAS, which is responsible for lipid synthesis (Loftus et al., 2000), and FAE showed downregulated expressions in muscle after interference with dsRNA on $E s-A c t R I I B$, indicating that lipid synthesis was inhibited in muscle, and energy was converted to support muscle growth. These results indicate that the balance of lipid metabolism was affected by RNAi of Es-ActRIIB.

\section{Conclusions}

In conclusion, $E s-A c t R I I B$ is a functionally conservative gene belonging to TGF- $\beta$ superfamily receptors, and its inhibition could positively regulate muscle growth by affecting protein synthesis and lipid metabolism. This study indicated the negative regulatory function of $A c t R I I B$ in E. sinensis. However, the molecular mechanism of ActRIIB signal transduction in E. sinensis must be clarified in future studies.

\section{References}

Abuhagr AM, MacLea KS, Mudron MR, Chang SA, Chang ES, Mykles DL. 2016. Roles of mechanistic target of rapamycin and transforming growth factor-beta signaling in the molting gland (Y-organ) of the blackback land crab, Gecarcinus lateralis. Comparative Biochemistry and Physiology Part A: Molecular and Integrative Physiology, 198: 15-21. DOI: 10.1016/j.cbpa.2016.03.018

Akpan I, Goncalves MD, Dhir R, Yin X, Pistilli EE, Bogdanovich S, Khurana TS, Ucran J, Lachey J, Ahima RS. 2009. The effects of a soluble activin type IIB receptor on obesity

Peer) reviewing PDF | (2020:01:44950:3:0:NEW 7 Jul 2020) 
363

364

365

366

367

368

369

370

371

372

373

374

375

376

377

378

379

380

381

382

383

384

385

386

387

388

389

390

391

392

393

394

395

396

397

398

399

400

401

402

and insulin sensitivity. International Journal of Obesity, 33: 1265-1273. DOI:

10.1038/ijo.2009.162

Bielohuby M. 2012. Fat news: a novel ActRIIB decoy receptor in the BAT-tle for obesity. Endocrinology, 153: 2939-2941. DOI: 10.1210/en.2012-1465

Chan S, Rankin SM, Keeley LL. 1988. Characterization of the molt stages in Penaeus vannamei: setogenesis and hemolymph levels of total protein, ecdysteroids, and glucose. The Biological Bulletin, 175: 185-192. DOI: 10.2307/1541558

Chen JL, Walton KL, Al-Musawi SL, Kelly EK, Qian H, La M, Lu L, Lovrecz G, Ziemann M, Lazarus R, El-Osta A, Gregorevic P, Harrison CA. 2015. Development of novel activintargeted therapeutics. Molecular Therapy, 23: 434-444. DOI: 10.1038/mt.2014.221

DeBose-Boyd RA. 2018. Significance and regulation of lipid metabolism. Seminars in Cell and Developmental Biology, 81: 97. DOI: 10.1016/j.semcdb.2017.12.003

Dumonceaux J, Marie S, Beley C, Trollet C, Vignaud A, Ferry A, Butler-Browne G, Garcia L. 2010. Combination of myostatin pathway interference and dystrophin rescue enhances tetanic and specific force in dystrophic mdx mice. Molecular Therapy, 18: 881-887. DOI: 10.1038/mt.2009.322

Dyson S, Gurdon JB. 1997. Activin signalling has a necessary function in Xenopus early development. Current Biology, 7: 81-84. DOI: 10.1016/s0960-9822(06)00030-3

Garg RR, Bally-Cuif L, Lee SE, Gong Z, Ni X, Hew CL, Peng C. 1999. Cloning of zebrafish activin type IIB receptor (ActRIIB) cDNA and mRNA expression of ActRIIB in embryos and adult tissues. Molecular and Cellular Endocrinology, 153: 169-181. DOI: 10.1016/s0303-7207(99)00044-1

Guru VP, Bhattacharya TK, Bhushan B, Kumar P, Chatterjee RN, Paswan C, Dushyanth K, Divya D, Prasad AR. 2019. In silico prediction of short hairpin RNA and in vitro silencing of activin receptor type IIB in chicken embryo fibroblasts by RNA interference. Molecular Biology Reports, 46: 2947-2959. DOI: 10.1007/s11033-019-04756-0

Han HQ, Zhou X, Mitch WE, Goldberg AL. 2013. Myostatin/activin pathway antagonism: molecular basis and therapeutic potential. The International Journal of Biochemistry and Cell Biology, 45: 2333-2347. DOI: 10.1016/j.biocel.2013.05.019

Hata A, Chen YG. 2016. TGF-beta signaling from receptors to smads. Cold Spring Harbor Perspectives in Biology, 8: a022061. DOI: 10.1101/cshperspect.a022061

Hellemans J, Mortier G, Paepe AD, Speleman F, Vandesompele J. 2007. qBase relative quantification framework and software for management and automated analysis of realtime quantitative PCR data. Genome Biology, 2007, 8: R19. DOI: 10.1186/gb-2007-8-2r19

Huang S, Chen X, Wang J, Chen J, Yue W, Lu W, Lu G, Wang C. 2017. Selection of appropriate reference genes for qPCR in the Chinese mitten crab, Eriocheir sinensis (Decapoda, Varunidae). Crustaceana, 90: 275-296. DOI: 10.1163/15685403-00003651

Huang S, Wang J, Yue W, Chen J, Gaughan S, Lu W, Lu G, Wang C. 2015. Transcriptomic variation of hepatopancreas reveals the energy metabolism and biological processes

Peer] reviewing PDF | (2020:01:44950:3:0:NEW 7 Jul 2020) 
403

404

405

406

407

408

409

410

411

412

413

414

415

416

417

418

419

420

421

422

423

424

425

426

427

428

429

430

431

432

433

434

435

436

437

438

439

440

441

442

associated with molting in Chinese mitten crab, Eriocheir sinensis. Scientific Reports, 5: 14015. DOI: $10.1038 /$ srep14015

Hulmi JJ, Oliveira BM, Silvennoinen M, Hoogaars WM, Ma H, Pierre P, Pasternack A, Kainulainen H, Ritvos O. 2013. Muscle protein synthesis, mTORC1/MAPK/Hippo signaling, and capillary density are altered by blocking of myostatin and activins. American Journal of Physiology. Endocrinology and Metabolism, 304: E41-50. DOI: 10.1152/ajpendo.00389.2012

Igarashi M, Watanabe K, Tsuduki T, Kimura I, Kubota N. 2019. NAPE-PLD controls OEA synthesis and fat absorption by regulating lipoprotein synthesis in an in vitro model of intestinal epithelial cells. The FASEB Journal, 33: 3167-3179. DOI: 10.1096/fj.201801408R

Klinbunga S, Janpoom S, Rongmung P, Prasertlux S, Srisuwan V, Menasveta P, Khamnamtong B. 2018. Characterization of transforming growth factor beta regulator 1-like and association between its expression levels and growth of the giant tiger shrimp Penaeus monodon. Comparative Biochemistry and Physiology Part B, Biochemistry and Molecular Biology, 225: 38-47. DOI: 10.1016/j.cbpb.2018.06.006

Koncarevic A, Kajimura S, Cornwall-Brady M, Andreucci A, Pullen A, Sako D, Kumar R, Grinberg AV, Liharska K, Ucran JA, Howard E, Spiegelman BM, Seehra J, Lachey J. 2012. A novel therapeutic approach to treating obesity through modulation of TGFbeta signaling. Endocrinology, 153: 3133-3146. DOI: 10.1210/en.2012-1016

Lee JH, Momani J, Kim YM, Kang CK, Choi JH, Baek HJ, Kim HW. 2015. Effective RNAsilencing strategy of Lv-MSTN/GDF11 gene and its effects on the growth in shrimp, Litopenaeus vannamei. Comparative Biochemistry and Physiology Part B: Biochemistry Molecular Biology, 179: 9-16. DOI: 10.1016/j.cbpb.2014.09.005

Li N, Yang Q, Walker RG, Thompson TB, Du M, Rodgers BD. 2016. Myostatin attenuation in vivo reduces adiposity, but activates adipogenesis. Endocrinology, 157: 282-291. DOI: 10.1210/en.2015-1546

Liu L, Long X, Deng D, Cheng Y, Wu X. 2018. Molecular characterization and tissue distribution of carnitine palmitoyltransferases in Chinese mitten crab Eriocheir sinensis and the effect of dietary fish oil replacement on their expression in the hepatopancreas. PLOS ONE, 13: e0201324. DOI: 10.1371/journal.pone.0201324

Liu ZH, Wu XJ, Long XW, Zhao L, Li JY, Cheng YX. 2016. Effects of fish oil replacement by vegetable oils in fattening diets on the related gene expression of fatty acid metabolism of about male Chinese mitten crab, Eriocheir sinensis (in Chinese). Acta Hydrobiological Sinica, 40: 765-778. DOI: 10.7541/2016.101

Loftus TM, Jaworsky DE, Frehywot GL, Townsend CA, Ronnett GV, Lane MD, Kuhajda FP. 2000. Reduced food intake and body weight in mice treated with fatty acid synthase inhibitors. Science, 288: 2379-2381. DOI: 10.1126/science.288.5475.2379

Massague J, Seoane J, Wotton D. 2005. Smad transcription factors. Genes and Development, 19: 2783-2810. DOI: 10.1101/gad.1350705 
443 Mathews LS, Vale WW, Kintner CR. 1992. Cloning of a second type of activin receptor and

444

445

446

447

448

449

450

451

452

453

454

455

456

457

458

459

460

461

462

463

464

465

466

467

468

469

470

471

472

473

474

475

476

477

478

479

480

481

482 functional characterization in Xenopus embryos. Science, 255: 1702-1705. DOI: 10.1126/science. 1313188

Morikawa M, Derynck R, Miyazono K. 2016. TGF-beta and the TGF-beta family: contextdependent roles in cell and tissue physiology. Cold Spring Harbor Perspectives in Biology, 8: a021873. DOI: 10.1101/cshperspect.a021873

Morrison PK, Bing C, Harris PA, Maltin CA, Grove-White D, Argo CM. 2014. Preliminary investigation into a potential role for myostatin and its receptor (ActRIIB) in lean and obese horses and ponies. PLOS ONE, 9: e112621. DOI: 10.1371/journal.pone.0112621

Morvan F, Rondeau JM, Zou C, Minetti G, Scheufler C, Scharenberg M, Jacobi C, Brebbia P, Ritter V, Toussaint G, Koelbing C, Leber X, Schilb A, Witte F, Lehmann S, Koch E, Geisse S, Glass DJ, Lach-Trifilieff E. 2017. Blockade of activin type II receptors with a dual anti-ActRIIA/IIB antibody is critical to promote maximal skeletal muscle hypertrophy. Proceedings of the National Academy of Sciences, 114: 12448-12453. DOI: 10.1073/pnas. 1707925114

Mykles D, Medler S. 2015. Natural History of Crustacea, Chapter: Skeletal muscle differentiation, growth, and plasticity. Oxford: Oxford University Press.

Nickel J, Ten Dijke P, Mueller TD. 2018. TGF-beta family co-receptor function and signaling. Acta Biochimica et Biophysica Sinica, 50: 12-36. DOI: 10.1093/abbs/gmx126

Rebbapragada A, Benchabane H, Wrana JL, Celeste AJ, Attisano L. 2003. Myostatin signals through a transforming growth factor beta-like signaling pathway to block adipogenesis. Molecular and Cellular Biology, 23: 7230-7242. DOI: 10.1128/mcb.23.20.72307242.2003

Sako D, Grinberg AV, Liu J, Davies MV, Castonguay R, Maniatis S, Andreucci AJ, Pobre EG, Tomkinson KN, Monnell TE, Ucran JA, Martinez-Hackert E, Pearsall RS, Underwood KW, Seehra J, Kumar R. 2010. Characterization of the ligand binding functionality of the extracellular domain of activin receptor type IIb. Journal of Biological Chemistry, 285: 21037-21048. DOI: 10.1074/jbc.M110.114959

Santibanez JF, Quintanilla M, Bernabeu C. 2011. TGF-beta/TGF-beta receptor system and its role in physiological and pathological conditions. Clinical Science, 121: 233-251. DOI: $10.1042 / \mathrm{CS} 20110086$

Shi Y, Massagué J. 2003. Mechanisms of TGF- $\beta$ signaling from cell membrane to the nucleus. Cell, 113: 685-700. DOI: 10.1016/s0092-8674(03)00432-x

Shinji J, Gotoh H, Miyanishi H, Lavine MD, Lavine LC. 2019. The activin signaling transcription factor Smox is an essential regulator of appendage size during regeneration after autotomy in the crayfish. Evolution and development, 21: 44-55. DOI: 10.1111/ede. 12277

Thompson TB, Woodruff TK, Jardetzky TS. 2003. Structures of an ActRIIB:activin A complex reveal a novel binding mode for TGF-beta ligand:receptor interactions. The EMBO Journal, 22: 1555-1566. DOI: 10.1093/emboj/cdg156 
483

484

485

486

487

488

489

490

491

492

493

494

495

496

497

498

499

500

501

502

503

504

505

506

507

508

509

510

511

512

513

514

515

516

517

518

519

520

521

522

Tian Z, Lin G, Jiao C. 2019a. Identification of a S6 kinase transcript in the Chinese mitten crab Eriocheir sinensis and its molting-related expression in muscle tissues. Fisheries Science, 85: 737-746. DOI: 10.1007/s12562-019-01326-y

Tian ZH, Jiao CZ, Cheng QX, Wu XG. 2018a. Molecular cloning, sequence analysis and tissue expression of serine/threonine kinases Akt from Eriocheir sinensis (in Chinese). Journal of Fisheries of China, 42: 485-494. DOI: 10.11964/jfc.20170110681

Tian ZH, Jiao CZ, Cheng YX. 2018b. Molecular cloning, sequence analysis, and tissue expression of Smad3-like protein from Eriocheir sinensis. Journal of Fishery Sciences of China, 25. DOI: 10.3724/sp.J.1118.2018.17155

Tian ZH, Peng HY, Deng WD, Jiao CZ. 2019b. Identification of a transforming growth factor- $\beta$ type I receptor transcript in Eriocheir sinensis and its molting-related expression in muscle tissues. Molecular Biology Reports, 47: 77-86. DOI: 10.1007/s11033-019-051088

Vandesompele J, Preter KD, Pattyn F, Poppe B, Roy NV, Paepe AD, Speleman F. Accurate normalization of real-time quantitative RT-PCR data by geometric averaging of multiple internal control genes. Genome Biology, 2002, 3: 1-12. DOI: 10.1186/gb-2002-3-7research0034

Wang J, Xu P, Zhou G, Li X, Lu Q, Liu X, Zhou J, Wang C. 2018. Genetic improvement and breeding practices for Chinese mitten crab, Eriocheir sinensis. Journal of the World Aquaculture Society, 49: 292-301. DOI: 10.1111/jwas.12500

Wang L, Yan B, Liu N, Li Y, Wang Q. 2008. Effects of cadmium on glutathione synthesis in hepatopancreas of freshwater crab, Sinopotamon yangtsekiense. Chemosphere, 74: 51-56. DOI: 10.1016/j.chemosphere.2008.09.025

Wei B, Yang Z, Cheng Y, Wang J, Zhou J. 2018. Effects of the complete replacement of fish oil with linseed oil on growth, fatty acid composition, and protein expression in the Chinese mitten crab (Eriocheir sinensis). Proteome Science, 16: 6. DOI: 10.1186/s12953-0180135-7

Xin XB, Yang SP, Li X, Liu XF, Zhang LL, Ding XB, Zhang S, Li GP, Guo H. 2019. Proteomics insights into the effects of MSTN on muscle glucose and lipid metabolism in genetically edited cattle. General and Comparative Endocrinology, 113237. DOI: 10.1016/j.ygcen.2019.113237

Yue W, Yang H, Chen Y, Wang J, Chen X, Hou X, Han H, Wang C. 2020. RNA interference provides insights into the multi-functional profiles of Es-MSTN gene in Eriocheir sinensis. Aquaculture Reports, 17. DOI: 10.1016/j.aqrep.2020.100310

Zhou Y-L, Li B, Xu Y-P, Wang L-Z, Gu W-B, Liu Z-P, Dong W-R, Shu M-A. 2019. The Activin-like ligand Dawdle regulates innate immune responses through modulating NF$\kappa \mathrm{B}$ signaling in mud crab Scylla paramamosain. Developmental and comparative immunology, 101: 103450. DOI: 10.1016/j.dci.2019.103450

Zhou Y-L, Wang C, Gu W-B, Zhu Q-H, Wang L-Z, Zhou Z-K, Liu Z-P, Chen Y-Y, Shu M-A. 2018. Identification and functional analysis of transforming growth factor- $\beta$ type I 
523

524

525

526

527

528

529 receptor (T $\beta \mathrm{R} 1$ ) from Scylla paramamosain: The first evidence of T $\beta \mathrm{R} 1$ involved in development and innate immunity in crustaceans. Developmental and comparative immunology, 88: 144-151. DOI: 10.1016/j.dci.2018.07.018

Zhuo RQ, Zhou TT, Yang SP, Chan SF. 2017. Characterization of a molt-related myostatin gene (FmMstn) from the banana shrimp Fenneropenaeus merguiensis. General and Comparative Endocrinology, 248: 55-68. DOI: 10.1016/j.ygcen.2017.03.010 


\section{Table $\mathbf{1}$ (on next page)}

Effects of RNAi on growth performance of juvenile mitten crab (means \pm SD)

“*” indicated significant difference $(P<0.05)$ and "**" indicated extremely significant difference $(P<0.01) ; B W_{1}$ : body weight after the first molt; $B W_{2}$ : body weight after the second molt; WGR: weight gain rate; SGR: specific growth rate; MI: molting interval time; HI: hepatosomatic index. 


\begin{tabular}{lll}
\hline Indicators of growth & $\operatorname{RNAi}(n=14)$ & Control $(n=14)$ \\
\hline$B W_{1}(\mathrm{~g})$ & $4.72 \pm 0.86$ & $4.54 \pm 0.85$ \\
$B W_{2}(\mathrm{~g})$ & $6.76 \pm 1.16$ & $5.86 \pm 1.28$ \\
$W G R(\%)$ & $43.87 \pm 8.23^{* *}$ & $28.57 \pm 8.60$ \\
$M I(\mathrm{~d})$ & $44.79 \pm 7.53$ & $50.14 \pm 7.44$ \\
$S G R(\% / \mathrm{d})$ & $0.84 \pm 0.26^{* *}$ & $0.51 \pm 0.16$ \\
$H I(\%)$ & $5.26 \pm 0.58$ & $7.09 \pm 0.55^{* *}$ \\
\hline
\end{tabular}

1 


\section{Table 2 (on next page)}

Amino acid composition in hepatopancreas and muscle of $E$. sinensis ( $\mathrm{g} / 100 \mathrm{~g}$, dry weight).

"*" indicated significant difference $(P<0.05)$ and "**" indicated extremely significant difference $(P<0.01)$; "A": essential amino acid; TEAA: total essential amino acid; TNEAA: total non-essential amino acid; TAA: total amino acid. 


\begin{tabular}{|c|c|c|c|c|}
\hline \multirow{2}{*}{ Amino acid } & \multicolumn{2}{|c|}{ Hepatopancreas } & \multicolumn{2}{|l|}{ Muscle } \\
\hline & RNAi & Control & RNAi & Control \\
\hline Asp & $2.70 \pm 0.02^{* *}$ & $2.49 \pm 0.04$ & $3.89 \pm 0.13^{*}$ & $3.52 \pm 0.13$ \\
\hline $\mathrm{Thr}^{\mathrm{A}}$ & $1.23 \pm 0.01^{* *}$ & $1.13 \pm 0.02$ & $1.78 \pm 0.07^{*}$ & $1.60 \pm 0.04$ \\
\hline Ser & $1.04 \pm 0.01^{* *}$ & $0.92 \pm 0.01$ & $1.69 \pm 0.05^{*}$ & $1.54 \pm 0.05$ \\
\hline Glu & $2.92 \pm 0.01^{* *}$ & $2.68 \pm 0.05$ & $5.49 \pm 0.14^{*}$ & $5.02 \pm 0.18$ \\
\hline Gly & $1.27 \pm 0.01^{* *}$ & $1.16 \pm 0.01$ & $2.16 \pm 0.08$ & $2.12 \pm 0.05$ \\
\hline Ala & $1.25 \pm 0.01^{* *}$ & $1.12 \pm 0.02$ & $2.39 \pm 0.08^{*}$ & $2.23 \pm 0.06$ \\
\hline $\mathrm{Val}^{\mathrm{A}}$ & $1.29 \pm 0.02^{* *}$ & $1.15 \pm 0.02$ & $2.01 \pm 0.08$ & $1.89 \pm 0.05$ \\
\hline $\mathrm{Met}^{\mathrm{A}}$ & $0.35 \pm 0.10$ & $0.28 \pm 0.20$ & $0.66 \pm 0.15^{* *}$ & $0.24 \pm 0.04$ \\
\hline $\mathrm{Ile}^{\mathrm{A}}$ & $0.88 \pm 0.02$ & $0.83 \pm 0.04$ & $1.67 \pm 0.02^{* *}$ & $1.54 \pm 0.04$ \\
\hline $\mathrm{Leu}^{\mathrm{A}}$ & $1.75 \pm 0.01^{* *}$ & $1.61 \pm 0.03$ & $2.77 \pm 0.06^{* *}$ & $2.54 \pm 0.06$ \\
\hline Tyr & $1.18 \pm 0.01^{* *}$ & $1.10 \pm 0.01$ & $1.68 \pm 0.10$ & $1.50 \pm 0.13$ \\
\hline $\mathrm{Phe}^{\mathrm{A}}$ & $1.24 \pm 0.04^{*}$ & $1.14 \pm 0.03$ & $1.49 \pm 0.10$ & $1.36 \pm 0.15$ \\
\hline $\mathrm{His}^{\mathrm{A}}$ & $0.60 \pm 0.02^{*}$ & $0.56 \pm 0.00$ & $1.13 \pm 0.03^{*}$ & $1.03 \pm 0.05$ \\
\hline Lys $^{\mathrm{A}}$ & $1.58 \pm 0.00^{* *}$ & $1.45 \pm 0.03$ & $2.59 \pm 0.09^{*}$ & $2.34 \pm 0.09$ \\
\hline Arg & $1.58 \pm 0.02^{*}$ & $1.54 \pm 0.02$ & $3.45 \pm 0.14^{*}$ & $3.17 \pm 0.08$ \\
\hline Pro & $1.11 \pm 0.02$ & $1.05 \pm 0.06$ & $2.19 \pm 0.10^{*}$ & $2.02 \pm 0.01$ \\
\hline TEAA & $8.93 \pm 0.08^{* *}$ & $8.15 \pm 0.22$ & $14.10 \pm 0.35^{*}$ & $12.53 \pm 0.45$ \\
\hline TNEAA & $13.06 \pm 0.05^{* *}$ & $12.04 \pm 0.11$ & $22.95 \pm 0.79^{*}$ & $21.14 \pm 0.62$ \\
\hline TEAA/TNEAA & $0.68 \pm 0.01$ & $0.68 \pm 0.02$ & $0.62 \pm 0.01^{* *}$ & $0.59 \pm 0.01$ \\
\hline TAA & $21.99 \pm 0.11^{* *}$ & $20.19 \pm 0.33$ & $37.06 \pm 1.13^{*}$ & $33.67 \pm 1.10$ \\
\hline
\end{tabular}

1 


\section{Table 3 (on next page)}

Fatty acid composition in hepatopancreas and muscle of E. sinensis (\% of total fatty acids).

$u^{* *}{ }^{*}$ indicated significant difference $(P<0.05)$ and ${ }^{u^{* *} \|}$ indicated extremely significant difference $(P<0.01)$; SFA: saturated fatty acid; MUFA: monounsaturated fatty acid; PUFA: polyunsaturated fatty acid. 


\begin{tabular}{|c|c|c|c|c|}
\hline \multirow{2}{*}{ Fatty Acid } & \multicolumn{2}{|c|}{ Hepatopancreas } & \multicolumn{2}{|l|}{ Muscle } \\
\hline & RNAi & Control & RNAi & Control \\
\hline C14:0 & $1.33 \pm 0.02$ & $1.40 \pm 0.01^{* *}$ & $1.30 \pm 0.05$ & $1.37 \pm 0.03$ \\
\hline $\mathrm{C} 15: 0$ & $0.61 \pm 0.01$ & $0.64 \pm 0.00^{* *}$ & $0.60 \pm 0.04$ & $0.59 \pm 0.08$ \\
\hline $\mathrm{C} 16: 0$ & $22.34 \pm 0.19^{*}$ & $21.56 \pm 0.25$ & $22.68 \pm 0.49$ & $21.86 \pm 0.0 .43$ \\
\hline $\mathrm{C} 17: 0$ & $0.37 \pm 0.01$ & $0.38 \pm 0.01$ & $0.44 \pm 0.06$ & $0.47 \pm 0.04$ \\
\hline C18:0 & $2.83 \pm 0.03$ & $2.79 \pm 0.04$ & $3.32 \pm 0.20$ & $3.71 \pm 0.32$ \\
\hline C20:0 & $0.24 \pm 0.00^{*}$ & $0.23 \pm 0.01$ & - & - \\
\hline $\mathrm{C} 21: 0$ & $0.24 \pm 0.01$ & $0.23 \pm 0.01$ & - & - \\
\hline $\mathrm{C} 22: 0$ & $0.25 \pm 0.01$ & $0.24 \pm 0.00$ & - & - \\
\hline $\mathrm{C} 23: 0$ & $0.36 \pm 0.03$ & $0.40 \pm 0.03$ & $0.94 \pm 0.23$ & $1.16 \pm 0.30$ \\
\hline $\mathrm{C} 24: 0$ & $0.15 \pm 0.01$ & $0.16 \pm 0.00$ & - & - \\
\hline SFA & $28.73 \pm 0.09^{*}$ & $28.02 \pm 0.26$ & $29.28 \pm 0.21$ & $29.16 \pm 0.12$ \\
\hline C14:1 & $0.21 \pm 0.01$ & $0.22 \pm 0.01$ & - & - \\
\hline C16:1 & $9.80 \pm 0.04^{* *}$ & $9.54 \pm 0.05$ & $8.99 \pm 018$ & $8.63 \pm 0.61$ \\
\hline C17:1 & $0.63 \pm 0.01$ & $0.68 \pm 0.00^{* *}$ & $0.54 \pm 0.01$ & $0.66 \pm 0.03^{* *}$ \\
\hline $\mathrm{C} 18: \ln 9 \mathrm{t}$ & $0.18 \pm 0.02$ & $0.23 \pm 0.04$ & - & - \\
\hline $\mathrm{C} 18: \ln 9 \mathrm{c}$ & $32.47 \pm 0.28^{* *}$ & $30.81 \pm 0.33$ & $31.74 \pm 0.16^{*}$ & $30.39 \pm 0.66$ \\
\hline C20:1n9 & $0.88 \pm 0.00^{* *}$ & $0.84 \pm 0.01$ & $0.87 \pm 0.02$ & $0.94 \pm 0.04$ \\
\hline $\mathrm{C} 22: \ln 9$ & $0.12 \pm 0.00$ & $0.16 \pm 0.00^{* *}$ & 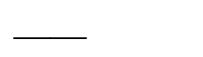 & 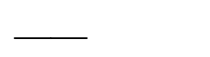 \\
\hline $\mathrm{C} 24: \ln 9$ & $0.45 \pm 0.02^{* *}$ & $0.35 \pm 0.03$ & - & - \\
\hline MUFA & $44.73 \pm 0.23^{* *}$ & $42.82 \pm 0.37$ & $42.15 \pm 0.33$ & $40.62 \pm 1.21$ \\
\hline $\mathrm{C} 18: 2 \mathrm{n} 6 \mathrm{c}$ & $21.63 \pm 0.05$ & $23.58 \pm 0.37^{* *}$ & $22.95 \pm 0.16$ & $23.29 \pm 0.48$ \\
\hline C18:2n6t & $0.12 \pm 0.00$ & $0.12 \pm 0.00$ & - & - \\
\hline $\mathrm{C} 18: 3 \mathrm{n} 3$ & $1.82 \pm 0.07$ & $2.22 \pm 0.11^{* *}$ & $2.10 \pm 0.06$ & $2.39 \pm 0.06^{* *}$ \\
\hline C18:3n6 & $0.37 \pm 0.02^{* *}$ & $0.30 \pm 0.00$ & - & - \\
\hline $\mathrm{C} 20: 2$ & $0.84 \pm 0.03$ & $0.83 \pm 0.01$ & $1.05 \pm 0.05$ & $1.05 \pm 0.07$ \\
\hline $\mathrm{C} 20: 3 \mathrm{n} 3$ & $0.22 \pm 0.02$ & $0.20 \pm 0.01$ & - & - \\
\hline $\mathrm{C} 20: 3 \mathrm{n} 6$ & $0.17 \pm 0.01^{*}$ & $0.08 \pm 0.05$ & - & - \\
\hline $\mathrm{C} 20: 4 \mathrm{n} 6$ & $0.10 \pm 0.01$ & $0.15 \pm 0.01^{* *}$ & - & - \\
\hline $\mathrm{C} 20: 5 \mathrm{n} 3$ & $0.64 \pm 0.04$ & $0.84 \pm 0.07^{*}$ & $1.57 \pm 0.39$ & $2.34 \pm 1.34$ \\
\hline $\mathrm{C} 22: 2$ & $0.14 \pm 0.03$ & $0.15 \pm 0.00$ & - & - \\
\hline $\mathrm{C} 22: 6 \mathrm{n} 3$ & $0.48 \pm 0.06$ & $0.64 \pm 0.07^{*}$ & $0.91 \pm 0.25$ & $1.14 \pm 0.23$ \\
\hline PUFA & $26.54 \pm 0.31$ & $29.10 \pm 0.58^{* *}$ & $28.57 \pm 0.54$ & $30.21 \pm 1.09$ \\
\hline$n-3$ & $3.17 \pm 0.19$ & $3.90 \pm 0.24^{*}$ & $4.57 \pm 0.61$ & $5.87 \pm 1.52$ \\
\hline$n-6$ & $22.40 \pm 0.08$ & $24.22 \pm 0.33^{* *}$ & $22.95 \pm 0.16$ & $23.29 \pm 0.48$ \\
\hline
\end{tabular}


Figure 1

Schematic diagram for structure prediction of Es-ActRIIB.

(A) Predicted domain structure of Es-ActRIIB. (B-C) Predicted protein structure of Es-ActRIIB. The $\alpha$-helix (red) and the $\beta$-sheet (yellow) were highlighted. The activin receptor domain (cyan) and the Serine/Threonine protein kinases domain (magenta) were highlighted.

A

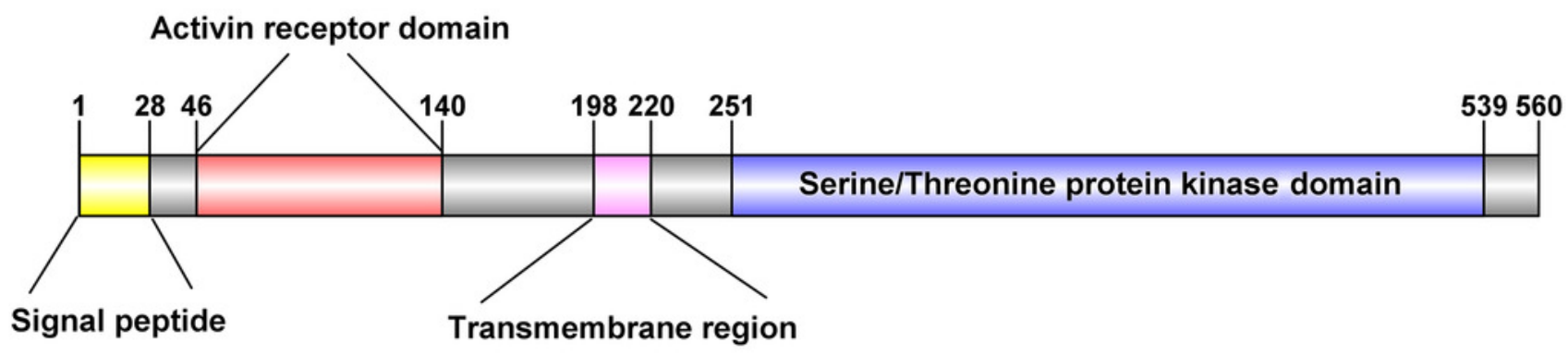

B

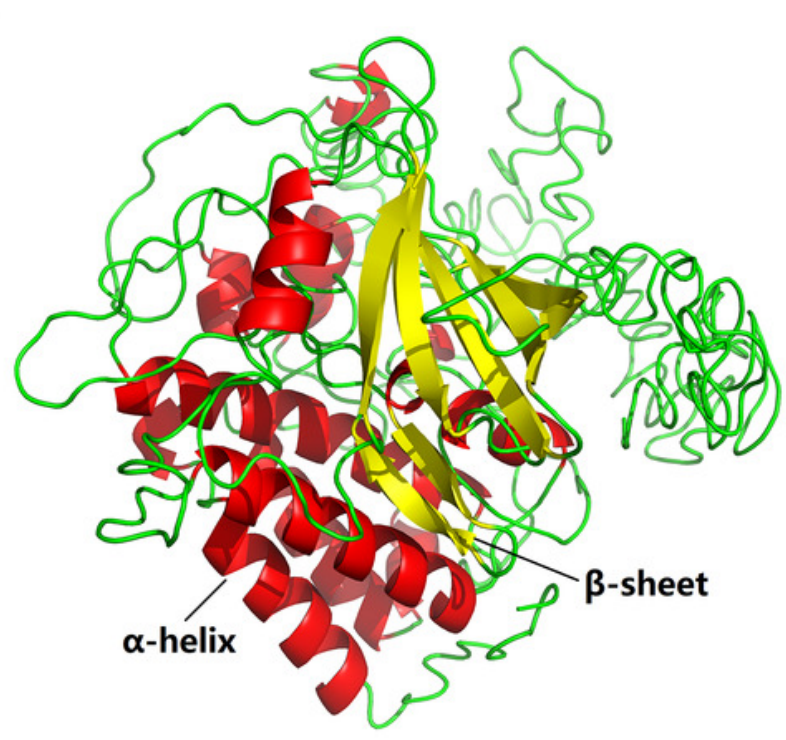

C Serine/Threonine

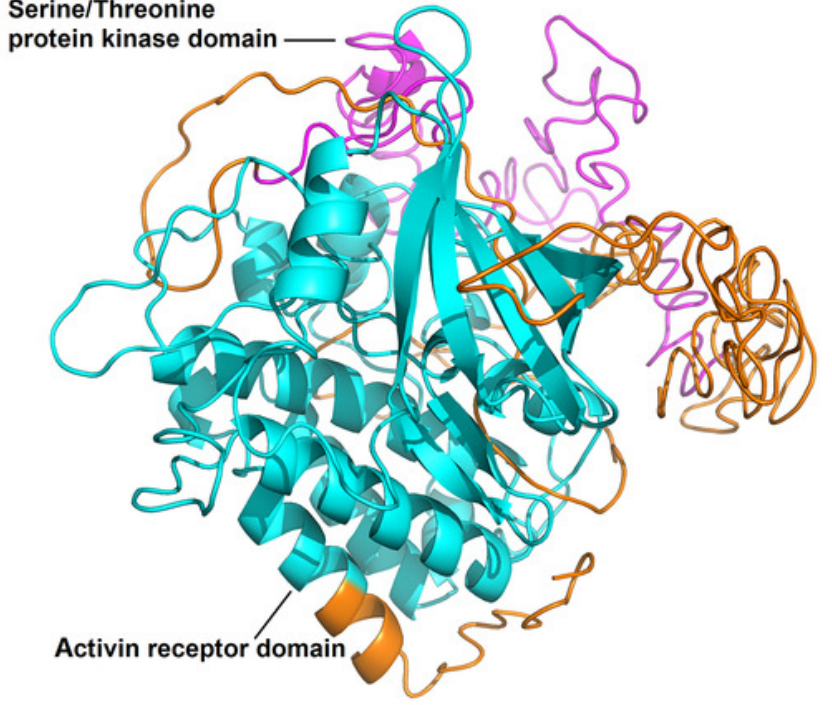


Figure 2

Phylogenetic tree based on ActRIIB protein sequences.

Colored ranges

Crustaceans

Insects

Fishes

Amphibians

Mammals

Reptiles

Birds

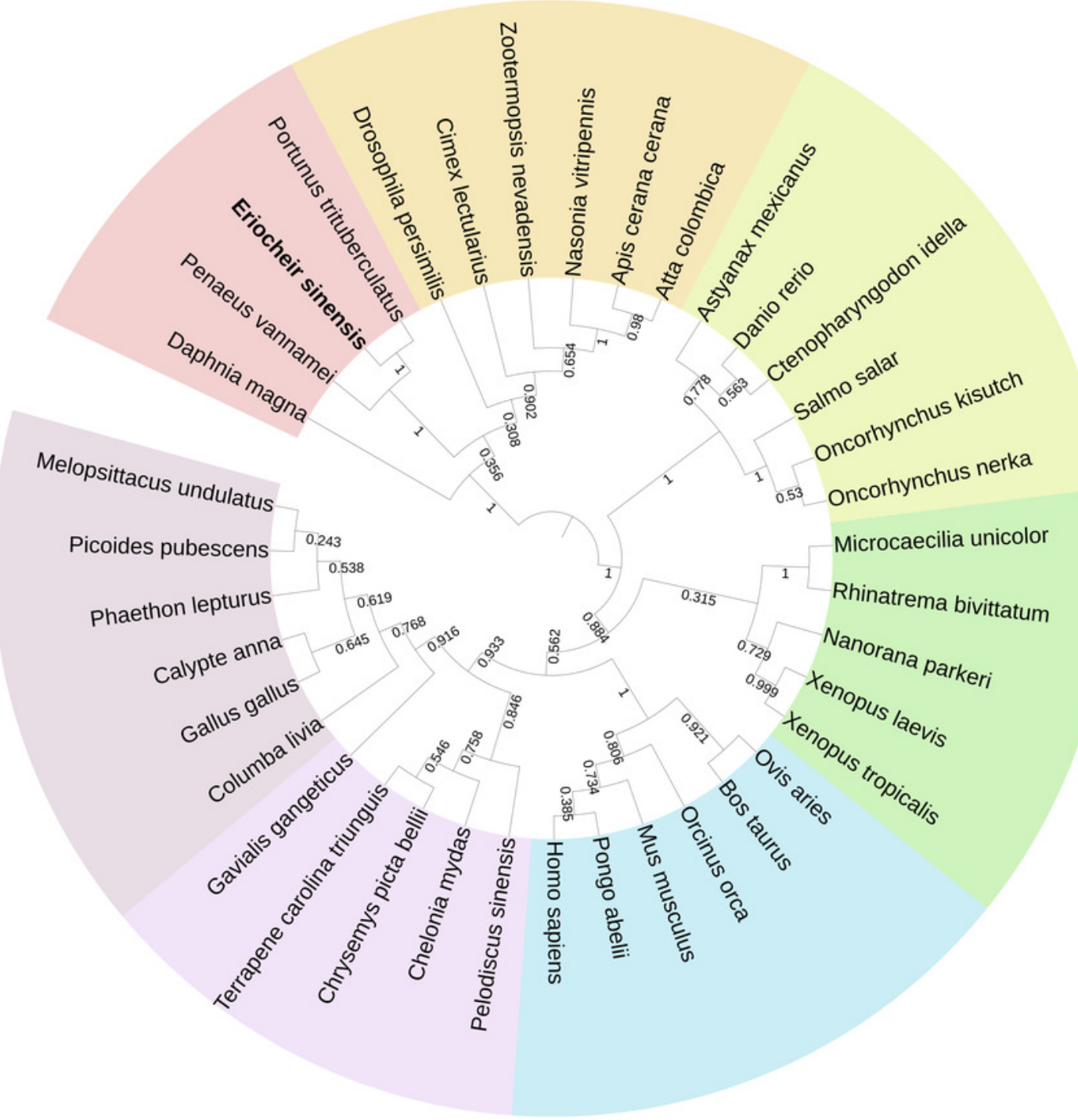




\section{Figure 3}

The expression profiles and comparison of Es-ActRIIB in different tissues and molting stages.

(A-D) The expression profiles of the 11 tissues at four molting stages, respectively. (E-H) Relative expression comparison among the four molting stages for relative tissues. PoM: postmolt stage; InM: intermolt stage; PrM: premolt stage; E: ecdysis stage; Es: eyestalk; Hp: hepatopancreas; Ht: heart; G: gill; S: stomach; I: intestine; Mw: walking leg muscle; Mc: claw muscle; Mp: pectoral muscle; Tg: thoracic ganglia; Ep: epidermis. Histogram plotted with mean and standard error. Different letters showed there were significant differences $(P<$ 0.05). 
A

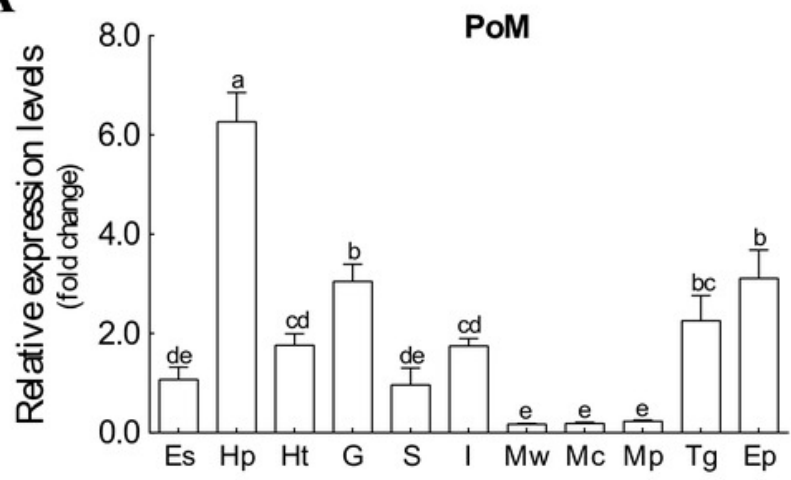

C

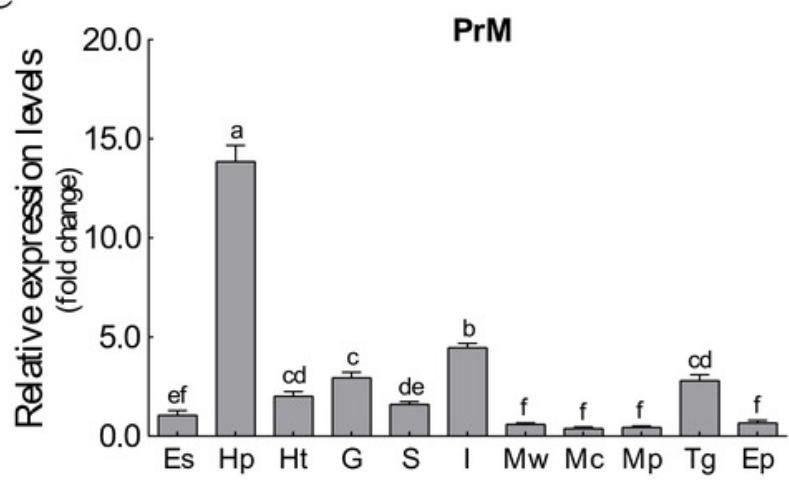

$\mathbf{E}$

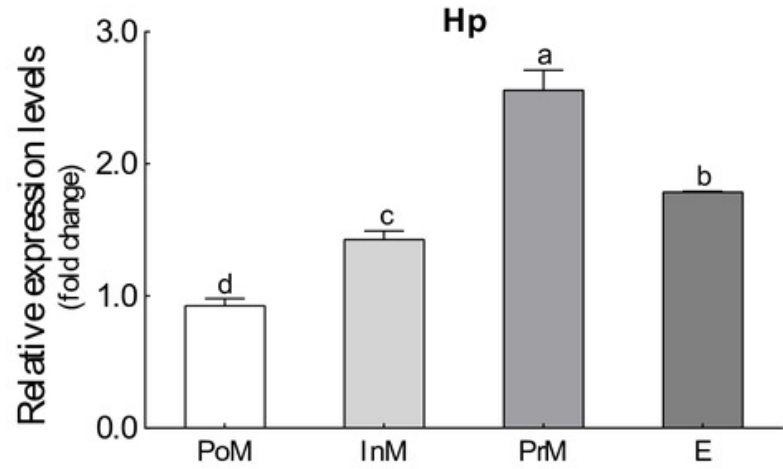

G

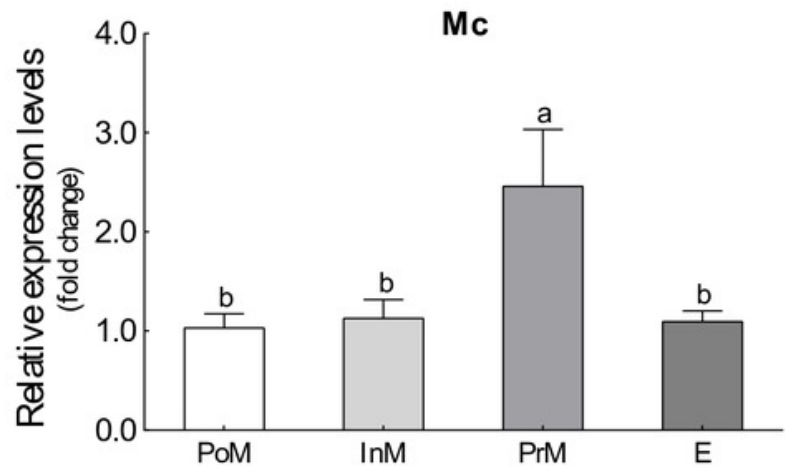

B

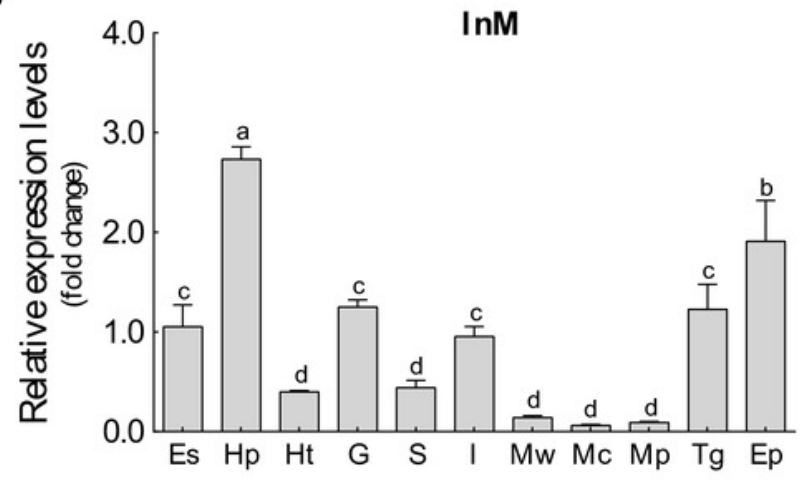

D

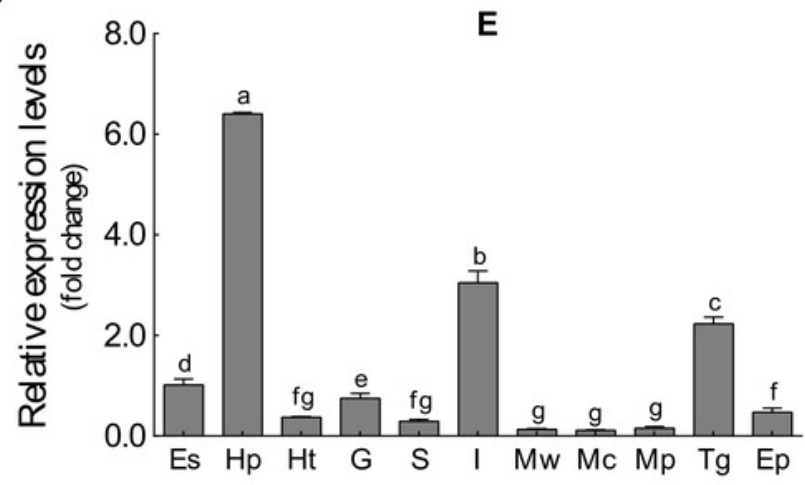

F

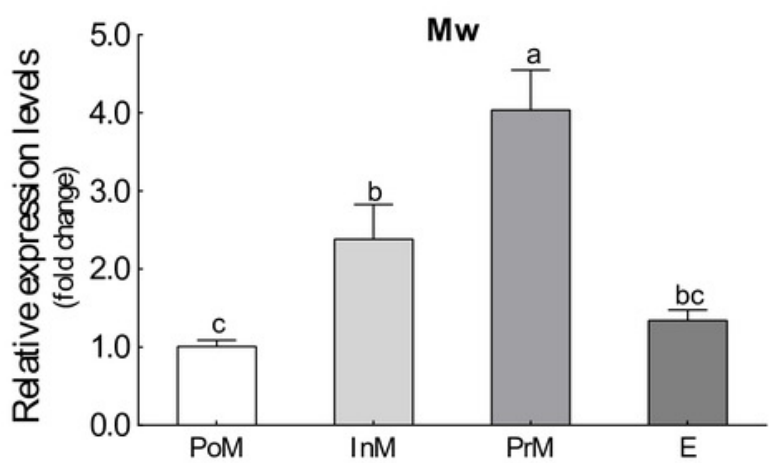

H

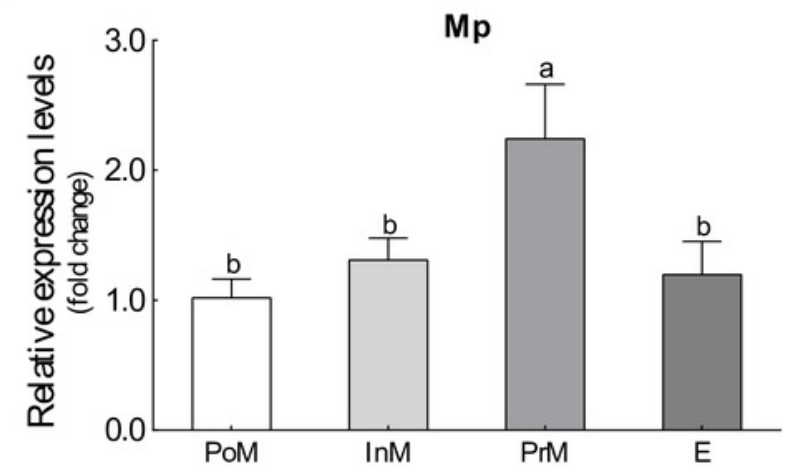


Figure 4

The interference efficiency of designed Es-ActRIIB dsRNA.

The different letters ( $a, b$ and $c$ ) indicated significant differences between hours after injection; “**" indicated extremely significant difference between two groups $(P<0.01)$.

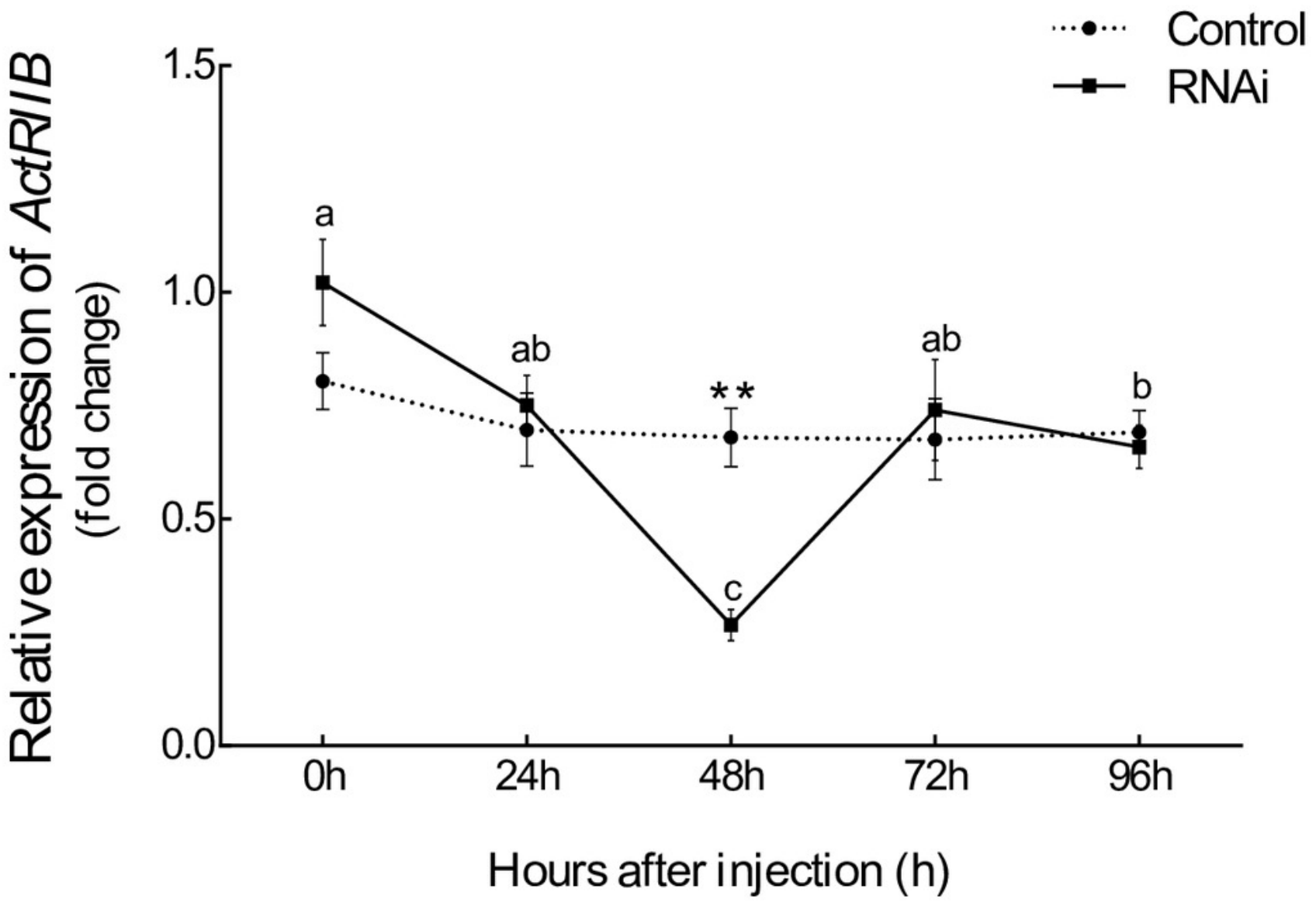


Figure 5

Expression changes of target genes after RNAi on Es-ActRIIB .

(A) ActRI. (B) SMAD3. (C) SMAD4. (D) FoxO. (E) mTOR. (F) CPTIB. (G) FAS. (H) FAE. "*”

indicated significant difference $(P<0.05)$ and "**" indicated extremely significant difference between two groups $(P<0.01)$. 
A

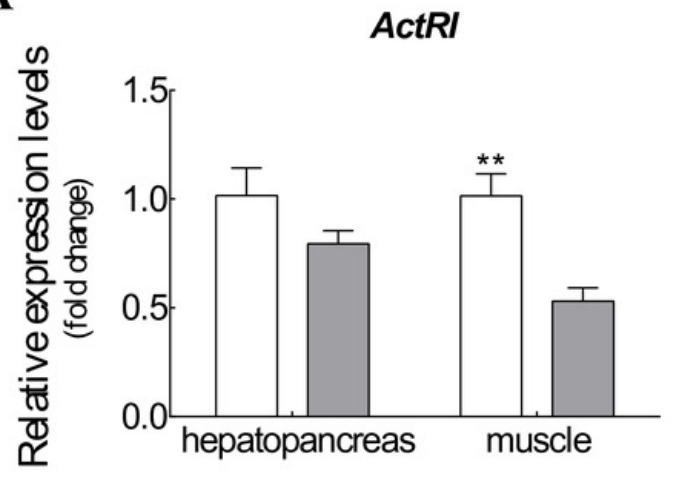

C

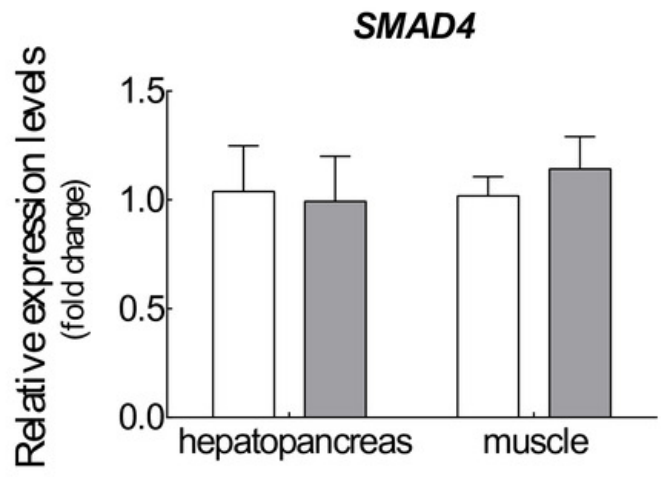

E

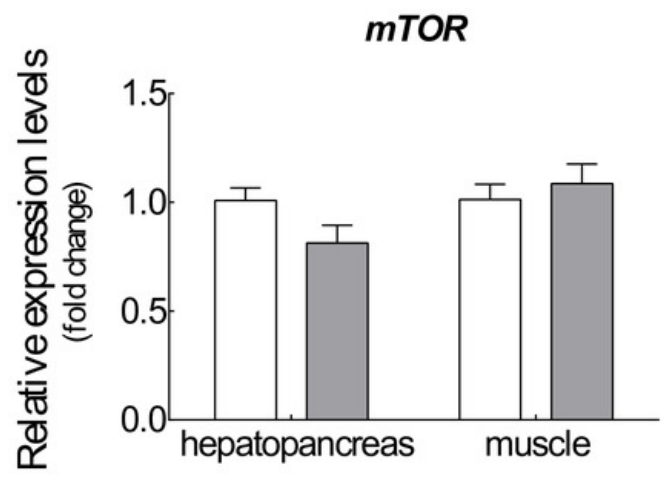

G

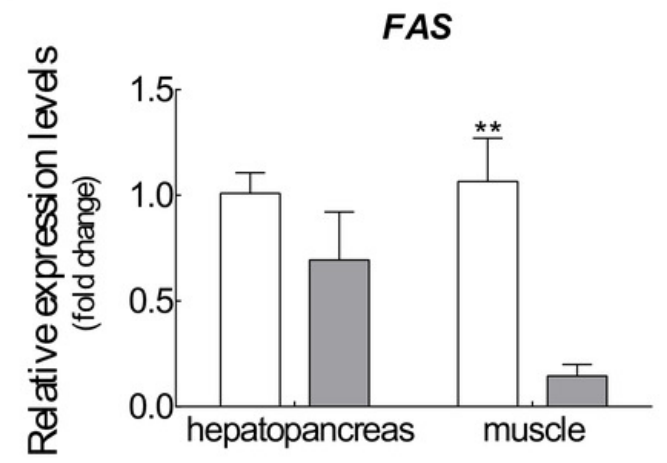

B

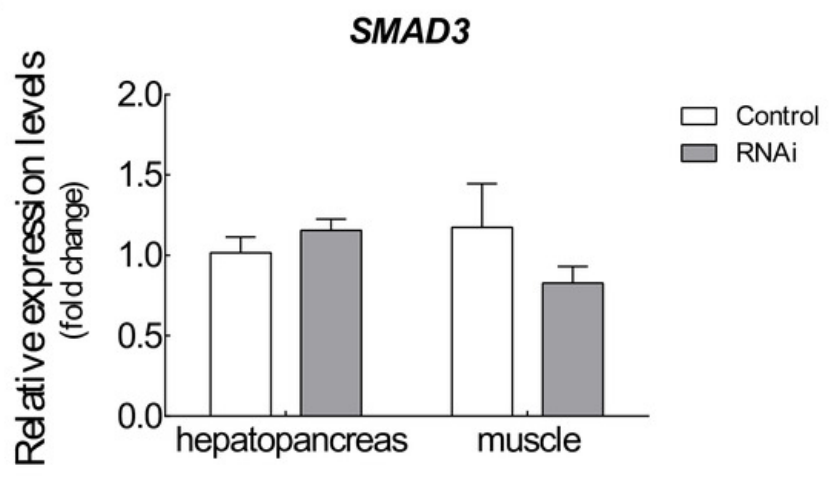

D

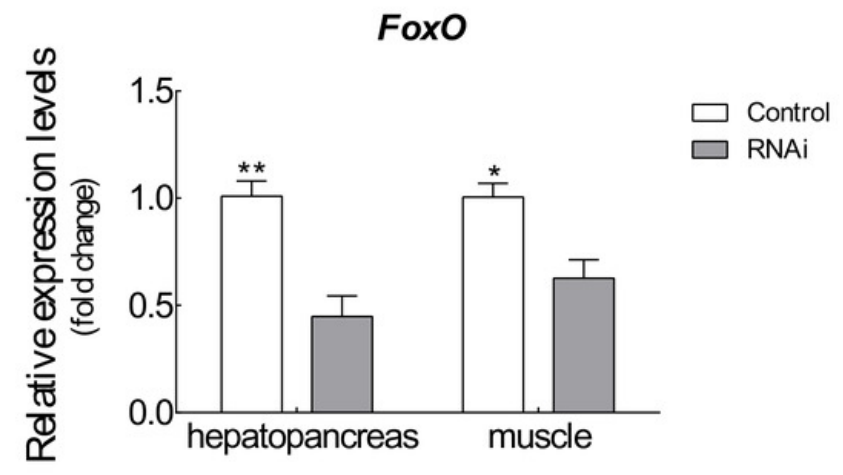

F

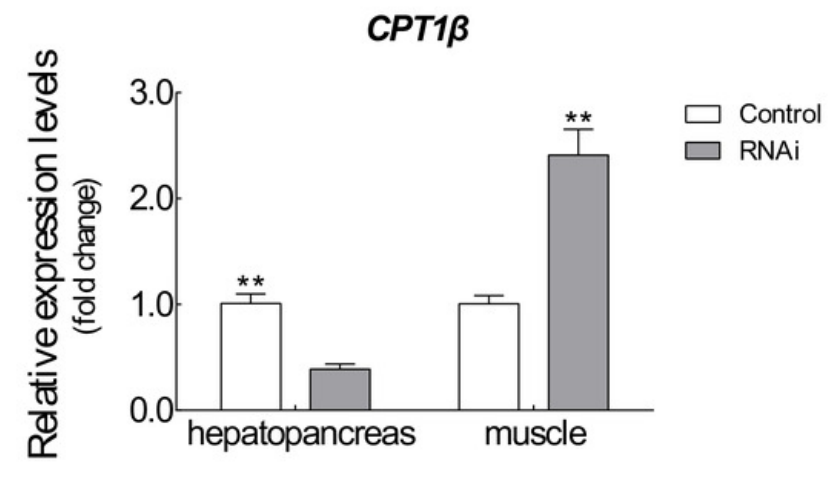

H

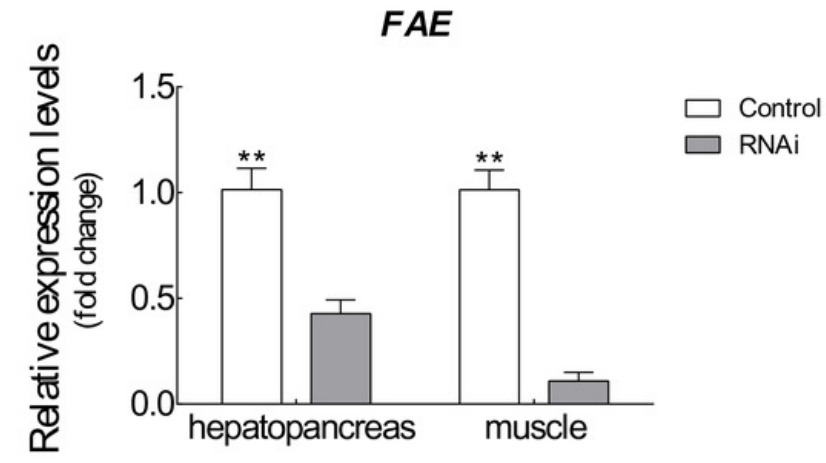

